\title{
El desarrollo económico comunitario Diagnóstico socioeconómico de cien comunidades
}

\author{
Aquiles Montoya
}

\section{Resumen}

En este artículo, el autor presenta un estudio sobre el nivel de desarrollo de 100 comunidades - ubicadas en 10 departamentos del país- conformadas por repatriados, repobladores y combatientes desmovilizados, a quienes se les considera parte de una nueva estrategia denominada Desarrollo Económico Comunitario. Estas comunidades buscan, de manera colectiva y organizada, desarrollar las actividades económicas para resolver sus problemas de pobreza y marginación. Aunque los resultados no son por completo satisfactorios, el autor considera que "la mayor riqueza del esfuerzo comunitario no está en lo logrado sino en sus posibilidades".

\section{Introducción}

El estudio está referido a cien comunidades ubicadas en 10 departamentos del país. Al estudiar este conjunto de comunidades no se pretende que constituyan el universo de las comunidades, ni tampoco que sean una muestra representativa estadísticamente de dicho universo. Sin embargo, sí se puede afirmar haber logrado estudiar a las comu- nidades organizadas más importantes del país. También se incluyeron más comunidades de aquellos departamentos que poseían más.

Con este diagnóstico socioeconómico se pretende llenar un gran vacío que existe en materia de Desarrollo Económico Comunitario (DEC), que consiste en no contar con un documento que muestre cuál es el estado o el nivel de desarrollo de las 
comunidades en el país, o al menos que lo haga de manera sistemática y que cubra a un gran número de comunidades, así como una gran diversidad de las mismas, en cuanto a su origen, ubicación, dedicación, organización, visión ideológico-política, etc.

Al contar con un universo de 100 comunidades, las cantidades que se presentan casi de manera general representan valores absolutos y porcentuales, cuando no sea así, se aclarará.

\section{Origen de las comunidades}

Las comunidades organizadas que, a nuestro juicio, son sujetas del desarrollo económico comunitario (DEC), se originan durante y después del conflicto político-militar, en consecuencia, se trata de un fenómeno de reciente fecha. Es importante tenerlo presente ya que, cuando hablamos de comunidades, no nos referimos a cualquier agrupamiento poblacional, como suelen hacerlo el gobierno, los organismos internacionales u otros organismos no gubernamentales. Desde nuestra perspectiva, las comunidades tienen su origen en las décadas de los ochenta y noventa, esto es, durante y después de la guerra. Además, su origen se explica en tres fenómenos muy precisos: las repatriaciones, las repoblaciones y los desmovilizados.

Por repatriaciones entendemos los fenómenos de conformación de una comunidad con población proveniente del exterior de nuestro país. Tales son, por ejemplo, las comunidades de Nueva Esperanza, conformada con población proveniente de Nicaragua; Guarjila, con repatriados provenientes de Mesa Grande en Honduras, o Ciudad Romero, con familias provenientes de Panamá. Pero todos ellos son salvadoreños y salvadoreñas que tuvieron que emigrar del país a causa de la guerra y las estrategias de tierra arrasada implementadas por el ejército gubernamental.

Las repoblaciones hacen referencia a las comunidades que se constituyen con población que sin haber abandonado el país, sí lo había hecho de su lugar de vivienda. En consecuencia, al ocurrir el fenómeno de la repoblación forman una nueva comunidad en un determinado lugar, el cual podría ser o no el que habían abandonado. Tales son, por ejemplo, Palo Grande y Milingo en Suchitoto.

Y los desmovilizados hacen referencia, principalmente, a los combatientes del FMLN que se desmovilizan a raíz del Acuerdo de Paz, pero tam- bién a algunos campesinos que integran el ejército gubemamental que se ven atraídos por la experiencia de sus antiguos adversarios. Ejemplos de ellos son las comunidades de Mariño II y Nuevo Amanecer en Usulután.

En las cien comunidades que se estudiaron, el factor más importante que explica el origen o la conformación de las comunidades es: la repoblación sola y la repoblación combinada con la desmovilización, que en conjunto casi representan el 50 por ciento del total de comunidades. También resulta sorprendente que una cuarta parte de las comunidades está constituida por desmovilizados, ya que cabría esperar que se hubieran integrado a las comunidades que ya existían, lo cual efectivamente ocurrió. Pero los desmovilizados también han dado origen a nuevas comunidades, lo que seguramente estuvo determinado por los lugares en donde se les brindó acceso a la tierra mediante el Programa de Transferencia de Tierra (PTT). Los datos se presentan en el Cuadro 1.

\section{Cuadro 1}

\section{Origen de las comunidades}

\begin{tabular}{lrlr}
\hline Repoblación & 22 & Repoblación y desmovilizados & 25 \\
Desmovilizados & 25 & Repoblación y repatriación & 3 \\
Repatriación & 9 & Repatriados y desmovilizados & 4 \\
Los 3 anteriores & 12 & Total & 100
\end{tabular}

De las comunidades que se crearon a partir de repatriaciones $y$ permanecen sin incluir a repobladores o desmovilizados sólo se encontraron nueve; sin embargo, hay 19 más que tuvieron su origen a partir de población repatriada, como se observa en el Cuadro 1 en las secciones de repoblación y repatriación, repatriación y desmovilizados y la que comprende la repatriación, repoblación y los desmovilizados. El resultado tiene sentido, seguramente resultaría extraño que las comunidades se hubiesen mantenido cerradas, ya que eran comunidades pequeñas en su mayoría. La comunidad cerrada se entiende cuando el núcleo poblacional inicial es bastante considerable, pero tales casos fueron excepcionales.

\section{Condición jurídica de las comunidades}

Con base en el actual Código Municipal, cualquier comunidad puede legalizarse o adquirir perso- 
nería jurídica mediante la creación de una asociación comunitaria, la elección de una junta directiva, la elaboración de un reglamento y llevando a cabo una asamblea general, a la cual asista el alcalde del municipio a la cual pertenezca la comunidad, y se levante un acta donde se de fe del acto de constitución de la asociación comunitaria. Gracias a este procedimiento bastante sencillo, la mayoria de comunidades existen legalmente, como se puede observar en el Cuadro 2.

\section{Cuadro 2}

Situación legal de las comunidades

\begin{tabular}{clr}
\hline ¿Cuál es la & Tienen personería jurídica & 75 \\
situación legal & No tienen personería jurídica & 7 \\
de la & En proceso de legalizar & 17 \\
comunidad? & No contestaron & 1 \\
\hline & Total & 100 \\
\hline
\end{tabular}

De las cien comunidades que visitamos, 75 tienen personería jurídica, 17 están en proceso de legalizar su situación y solamente 7 manifestaron que no la tenían ni están en proceso de obtenerla, lo cual indica que un porcentaje elevado, el 82 por ciento, tiene o va a tener su personería jurídica. Este hecho resulta bastante satisfactorio ya que recién finalizado el conflicto, pese a lo fácil del procedimiento para legalizar su situación, muchos alcaldes se negaban a cumplir con su obligación municipal, ya sea por razones políticas o, bien, porque aún no retomaban a sus localidades.

Este elemento jurídico es bastante importante a fin de captar créditos como comunidad, o bien, para legalizar la propiedad de bienes o activos (tierra, maquinaria, edificios, etc.) que han sido donados a la comunidad o adquiridos por ésta en el mercado. Con ello no se sostiene que la problemática de la propiedad, o la discusión en torno a cuál es la forma más adecuada, ya queda resuelta, pero sí que al menos existe un ente jurídico colectivo con capacidad para ser propietario. Que el punto no se resuelve lo evidencia el hecho de que algunas comunidades, además de la personería jurídica, han creado asociaciones y sociedades cooperativas para legalizar la propiedad de sus bienes.

\section{La conciencia comunitaria y las relaciones intercomunitarias}

La conciencia comunitaria se manifiesta en una cantidad de hechos, sin embargo, nosotros la hemos explorado solamente en tres aspectos: el laboral, el social y el gremial.

Nos parece que tal forma de vida no aparece por generación espontánea, que requiere de trabajo, educación, práctica, mucha voluntad y mucho tiempo. De allí que, en aquellas comunidades con una mayor vida, los niveles de conciencia pudieran ser mayores, si es que se dan los otros factores. Pero también incide en la conciencia comunitaria el origen de la comunidad. Así, aquellas comunidades que se formaron a partir de una repatriación generalmente presentan mayores niveles de conciencia. Tal fenómeno se explica a partir del hecho de que a estas comunidades se les repatría como comunidades y, en esa medida, traen consigo toda la vivencia comunitaria formada durante los años de exilio. Pero bien, con todo y lo difícil que resulta captar cuál es la conciencia sobre las ventajas de vivir en comunidad, veamos la información del Cuadro 3.

\section{Cuadro 3}

Nivel de conciencia de las ventajas de vivir en comunidad

\begin{tabular}{lccc}
\hline & Trabajo & Social & Gremial \\
\hline Alto & 24 & 38 & 32 \\
Medio & 44 & 46 & 36 \\
Bajo & 28 & 12 & 28 \\
No contestaron & 4 & 4 & 4 \\
\hline Total & 100 & 100 & 100 \\
\hline
\end{tabular}

A pesar de que las comunidades que tuvieron su origen en las repatriaciones son la minoría y que las originadas en las repoblaciones y desmovilizados tienen un menor tiempo de vida, los resultados correspondientes al nivel alto son bastante sorprendentes por lo significativos; en lo social cubre a más de un tercio de las comunidades; en lo gremial, a un tercio, y en lo laboral, a casi una cuarta parte de las comunidades.

Dada la composición de las comunidades estudiadas, en cuanto a su origen y tiempo de vida, los datos correspondientes al nivel medio parecen ser los esperados. Son datos satisfactorios que al combinarse con los del nivel alto, nos presentan un panorama bastante esperanzador de cara a la vivencia futura de las comunidades. Casi podría afimarse que 
el futuro comunitario está asegurado, si éste dependiera exclusivamente de la conciencia que se tenga acerca de las ventajas de vivir en comunidad.

\section{Figura 1}

Tipo de relaciones de las comunidades entre sí

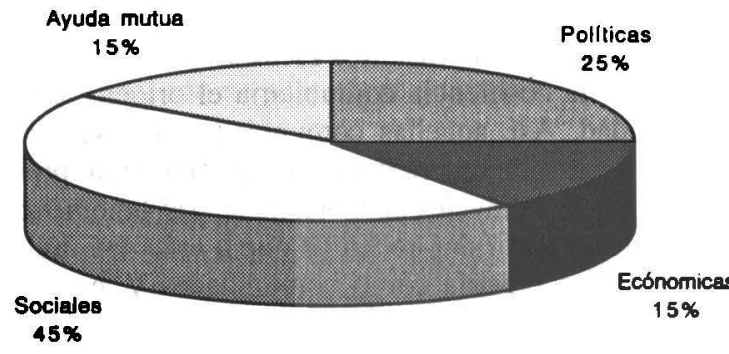

Ahora bien, pensando en el futuro de las comunidades nos pareció importante determinar cómo están sus relaciones y establecimos que las que ocupan un mayor lugar de importancia son las relaciones sociales, seguidas de las relaciones políticas y de las económicas y de ayuda mutua, las cuales se ubican en un mismo nivel. Sin embargo, pensamos que el orden se debería invertir a fin de avanzar hacia la articulación inter e intrasectorial. Es decir, que las relaciones económicas no sólo deberian incrementarse entre las comunidades, sino que además deberían de profundizarse las existentes. Gran parte del éxito de las comunidades dependerá de la articulación económica que logren entre sí (ver la Figura 1).

\section{Población y familias en las comunidades}

Decíamos que el estudio se ha ocupado de cien comunidades en diez departamentos, de los catorce que tiene el país, y dejamos por fuera a los tres departamentos occidentales - Santa Ana, Sonsonate y Ahuachapán- y al departamento más oriental: La Unión. La decisión no fue caprichosa, sino que respondio al hecho de que al no haberse desarrollado el conflicto en el occidente, en éste no hubo repoblaciones ni repatriaciones. En cuanto al departamento de La Unión, en él ocurrió algo semejante aunque no estuvo totalmente libre del conflicto; pese a ello, no logramos detectar comunidades organizadas que hubiesen surgido durante las décadas de los ochenta y noventa, razón por la cual decidimos prescindir de tal departamento.

En las cien comunidades detectamos una po- blación total de 56,486 personas y 11,337 familias, con una población promedio por comunidad de 565 personas y 113 familias (ver Cuadro 4).

\section{Cuadro 4}

Población y familias en las comunidades

\begin{tabular}{lcrr}
\hline Departamento & $\begin{array}{c}\text { Número de } \\
\text { comunidades }\end{array}$ & $\begin{array}{c}\text { Número de } \\
\text { familias }\end{array}$ & $\begin{array}{r}\text { Número de } \\
\text { personas }\end{array}$ \\
\hline Cabañas & 4 & 731 & 4908 \\
Chalatenango & 14 & 1,983 & 11,068 \\
Cuscatlán & 17 & 891 & 3,923 \\
La Libertad & 3 & 227 & 1,115 \\
La Paz & 2 & 145 & 740 \\
Morazán & 5 & 1,579 & 8,269 \\
San Miguel & 10 & 2,337 & 9,349 \\
San Salvador & 10 & 3,741 & 3,561 \\
San Vicente & 11 & 741 & 3,561 \\
Usulután & 24 & 2,305 & 11,696 \\
\hline Total & 100 & 11,337 & 56,486 \\
\hline
\end{tabular}

Los departamentos con mayores comunidades son aquellos en los cuales el conflicto bélico tuvo mayor beligerancia, como Usulután, Cuscatlán, Chalatenango, San Miguel, San Vicente y San Salvador. Por ello es que en Chalatenango aparecen como comunidades organizadas algunos municipios importantes de la zona nororiental del departamento, como Arcatao, San José Las Flores y San Antonio Los Ranchos.

Los departamentos con más comunidades y más población son, precisamente, los seis mencionados con anterioridad. La no correspondencia entre la magnitud de las comunidades y la población se explica porque al no dejar de lado las comunidades más importantes, se incluyeron en algunos departamentos comunidades relativamente grandes, como Santa Marta, en Cabañas, con 4,000 personas; Guarjila y Arcatao, en Chalatenango, con 4,300 entre las dos; Segundo Montes, en Morazán, con 7,421; y Las Marías y Las Moritas, en San Miguel, con 6,160 entre ambas. Con su sola presencia se introduce cierto sesgo a la correspondencia porcentual que pudiera existir entre el número de comunidades y la población por departamento, así tenemos, a modo de ejemplo, Cabañas, con 4 por ciento de comunidades y 8.68 por ciento de población; Cuscatlán, con 17 por ciento de comunidades y 6.94 por ciento de población; Morazán, con 5 por ciento de comunidades y 14.63 por ciento de población; y San Miguel, con 10 
por ciento de comunidades y 16.55 por ciento de población.

Ahora bien, nos interesa destacar que aun suponiendo que no hubieran más comunidades, lo cual no es así, el universo poblacional que integra esta alternativa de desarrollo económico comunitaria es bastante significativa, ya que estaríamos considerando, al menos, a 56 mil personas. Pero se sabe, por ejemplo, que sólo el Sistema Económico Social, un conjunto de 15 comunidades, radicadas en el sur de Tecoluca, departamento de San Vicente, tiene alrededor de 4,000 personas y en nuestro estudio sólo hemos incluido la población de unas pocas comunidades.

\section{La tierra en las comunidades}

En la medida que se trata de comunidades rurales, la tierra ocupa un lugar preponderante en las mismas, ya que su vida, su trabajo, su cultura, su ser social y material se asocian íntimamente con la tierra, sino es que depende totalmente de la misma. En consecuencia, importa conocer cuál es su relación con la tierra y también cuál es la calidad de ésta.

En primer lugar, hay que conocer cuál es la relación jurídica de las comunidades con la tierra, lo cual está captado perfectamente en el Cuadro 5.

\section{Cuadro 5}

Tenencia de la tierra

\begin{tabular}{clc}
\hline ¿Cuál es la & Propia & 55 \\
situación legal & $\begin{array}{l}\text { Pendiente de transferencia } \\
\text { de la tierra? }\end{array}$ & $\begin{array}{l}\text { Propia y en proceso } \\
\text { de transferencia }\end{array}$ \\
\hline & Total & 33 \\
\hline
\end{tabular}

Del total de comunidades visitadas, 55 reportaron que la tierra era propia, 33 que era propia y estaba en proceso de transferencia, lo cual nos indica que sólo en el 12 por ciento de las comunidades restantes la tierra no era de su propiedad. La resultante es que, al menos, en estas cien comunidades visitadas, la propiedad de la tierra prácticamente ha dejado de ser un problema, lo que abre muchas posibilidades de cara a las mejoras, la conservación $y / 0$ recuperación de la tierra. $Y$ es que cuando el trabajador agricola no es propietario de la tierra, es mucho más difficil que invierta en la misma o que realice obras de conservación del suelo. Igualmente, la propiedad de la tierra proporciona a estas comunidades un mayor sentido de permanencia. Es posible pensar que los hijos y los nietos le darán continuidad a sus esfuerzos y que, incluso, se beneficiarán de los mismos, lo cual no sería posible si fueran tan sólo arrendatarios. Por otra parte, el hecho de ser propietarios de la tierra también puede verse como un triunfo de las comunidades, como una meta o un objetivo alcanzado; como un bien dentro de tanto mal que dejó la guerra.

En segundo lugar, tenemos la calidad de la tierra, la cual de manera general ha sido calificada como excelente, buena, regular y mala, resultando ambos extremos como los menos relevantes, como se observa en el Cuadro 6.

\section{Cuadro 6}

Calidad agrícola de la tierra

\begin{tabular}{|c|c|c|}
\hline $\begin{array}{c}\text { ¿Cuál es } \\
\text { la calidad } \\
\text { agrícola } \\
\text { de la tierra? }\end{array}$ & $\begin{array}{l}\text { Excelente } \\
\text { Buena } \\
\text { Regular } \\
\text { Mala } \\
\text { Excelente y regular } \\
\text { Buena y regular } \\
\text { Buena, regular y mala } \\
\text { No contestaron }\end{array}$ & $\begin{array}{r}2 \\
24 \\
54 \\
11 \\
1 \\
2 \\
1 \\
5\end{array}$ \\
\hline & Total & 100 \\
\hline
\end{tabular}

Una cuarta parte de las comunidades considera la tierra que trabajan como buena, el 54 por ciento como regular, el 2 por ciento como excelente y sólo el 11 por ciento como mala, lo cual se presenta como un hecho importante, ya que indica que para la mayoría de las comunidades es posible vivir de la agricultura, aunque no sin algún esfuerzo. Para una mejor comprensión de lo anterior, es necesario que completemos el análisis de la calidad de la tierra con la topografía del terreno en las comunidades, información que presentamos en el Cuadro 7.

Cuadro 7

Topografía del terreno

\begin{tabular}{llr} 
¿Cuál es la & Plano & 17 \\
topografia & Semiplano & 29 \\
del terreno? & Quebrado & 35 \\
& Variado & 19 \\
\hline & Total & 100 \\
\hline
\end{tabular}


La información obtenida es que en el 61 por ciento de las comunidades el terreno es plano o semiplano, lo cual ciertamente al no tratarse de terrenos desérticos ni pantanosos -como lo sabemos - nos permite sostener que, al menos, en el 61 por ciento de las comunidades es posible trabajar en labores agrícolas en condiciones que van de excelentes a regulares, sin generar mayores problemas por erosión, ya que no se realizan de manera importante cultivos agrícolas anuales en laderas.

Cabría agregar que la información presentada respecto a la calidad y topografía de la tierra es la predominante en cada comunidad pero no la única, aunque excepcionalmente pudiera darse el caso de una comunidad en la que toda su tierra fuera plana y de excelente calidad, como es el caso de la comunidad Las Canoas en el sur de Usulután, o bien que sea mala y quebrada, como lo es la tierra en la comunidad Segundo Montes en el norte de Morazán.

\section{Las técnicas agrícolas}

Es importante conocer cuál es la relación técnica entre los productores comunitarios y la tierra. Para ello exploramos dos técnicas posibles: la que surgió de la revolución verde y la de la agricultura orgánica. La primera se caracteriza por el uso de productos químicos, como fertilizantes, fungicidas, insecticidas y herbicidas. La segunda, como lo indica su nombre, está determinada por el uso de productos orgánicos.

\section{Cuadro 8}

Técnicas agricolas en las comunidades

\begin{tabular}{lcccccc}
\hline & Más del 50\% & El 50\% & Menos del 50\% & No usan & No contesta \\
\hline Usan químicos & 86 & 5 & 2 & 2 & 5 \\
Usan fertilizantes orgánicos & 7 & 6 & 38 & 43 & 6 \\
Combinan químicos y orgánicos & 12 & 8 & 24 & 47 & 9 \\
Usan semilla mejorada & 72 & 10 & 9 & 5 & 4 \\
\hline
\end{tabular}

Pues bien, los resultados que obtuvimos nos indican que las comunidades se encuentran bajo la influencia de las técnicas introducidas por la Revolución Verde; por otro lado, el campesino es bastante reacio al cambio, de allí que cuando lo hace, resulta bastante difícil hacerlo cambiar de nuevo. Y es que las técnicas de la Revolución Verde casi se las impusieron a los campesinos, vía mecanismos crediticios y ayuda en insumos condicionados al uso de las nuevas técnicas, por una parte, y por otra, a causa de la pérdida de fertilidad natural de la tierra se presentó la urgente necesidad de utilizar los fertilizantes químicos, luego que se suspendiera la importación del guano peruano.

Pese a que predominantemente los campesinos usan insumos químicos y semilla mejorada, en algunas comunidades existe la agricultura orgánica. Porque si bien es cierto que en 86 comunidades más de la mitad usa productos químicos, existen 7 en donde más del 50 por ciento ya usa fertilizantes orgánicos, lo cual constituye como el primer paso hacia la agricultura orgánica. Además, hay 12 comunidades donde más de la mitad de los agricultores combinan los productos químicos con los orgá- nicos. Pero también existen 6 comunidades donde la mitad de los campesinos usan fertilizantes orgánicos y 8 combinan los productos químicos con los orgánicos.

Pero si a estas comunidades les sumamos aquellas en las cuales menos de la mitad usan fertilizantes orgánicos o combinan químicos con orgáni$\cos$, tenemos que el desarrollo de la agricultura orgánica ya es significativo, sobre todo si se tienen en cuenta los riesgos que se corren al pasar de una técnica a otra. ¿Usted cambiaría fácilmente de actividad profesional? Seguramente, no sin algunas dificultades, si es que se hace el cambio. Sin embargo, algo equivalente le pedimos a los trabajadores agrícolas.

También resulta interesante constatar que los agricultores, en las comunidades estudiadas, aplican en su mayoría algún nivel tecnológico en sus cultivos como fruto de la Revolución Verde, ya que aquellos que no usan insumos químicos ni semilla mejorada constituyen una proporción muy baja, apenas el 2 y el 5 por ciento, respectivamente. $O$ bien, al utilizar otro indicador tecnológico, como la práctica de los análisis de suelos, encontramos que en el 
67 por ciento de las comunidades se acostumbra realizar tales análisis. Práctica de suyo muy interesante y que sigue siendo muy útil, inclusive, cuando se avanza hacia la agricultura orgánica.

\section{Problemas y soluciones ambientales}

Intimamente vinculados con la tierra y las técnicas agrícolas están los problemas de deforestación, erosión y contaminación de las aguas, por ejemplo. De allí que antes de analizar cualquier otra problemática, deseamos ocupamos de algunos de los problemas ambientales que enfrentan las comunidades, así como también de las posibles soluciones, esto es, de aquellos programas y capacitaciones que no sólo tienen relación con su economía, sino también con sus vidas.

De manera general cabría señalar que la problemática, en materia ambiental, que presentan las comunidades es menos grave que aquella que se presenta como una triste realidad a nivel nacional, excepción hecha a la deforestación que alcanza niveles bastante altos y está presente en el 87 por ciento de las comunidades estudiadas. Pero esto no podía ser de otra manera, al menos por ahora, ya que el pais está grave y seriamente deforestado, aunque a futuro podría variar ya que en las comunidades sí existe una real preocupación por los problemas ambientales y particularmente por la deforestación.

Cuadro 9

Problemas y soluciones ambientales

\begin{tabular}{lccc}
\hline & Sí & No & No contesta \\
\hline Problemas & & & \\
Deforestación & 87 & 12 & 1 \\
Agua contaminada & 36 & 59 & 5 \\
Erosión & 62 & 37 & 1 \\
Deslaves o cárcavas & 22 & 73 & 5 \\
Tierras pantanosas & 47 & 47 & 6 \\
Cultivos en laderas & 50 & 46 & 4 \\
Programas & & & \\
De reforestación & 52 & 45 & 3 \\
Para evitar erosión & 47 & 29 & 24 \\
$\begin{array}{l}\text { Capacitación } \\
\text { Asistencia técnica }\end{array}$ & 83 & 13 & 4 \\
Talleres s/ medio & & & \\
ambiente & 54 & 46 & - \\
Realizan análisis de suelos & 67 & 31 & 2 \\
\hline
\end{tabular}

En el ámbito de las comunidades, objeto de nuestro estudio, a la deforestación le sigue en orden de importancia la erosión, la cual está presente en el 62 por ciento de éstas. Y es que si hay deforestación tiene que haber erosión. Afortunadamente existen programas para enfrentar ambos problemas que, si bien no están presentes en la totalidad de las comunidades afectadas, cubren alrededor del 50 por ciento de las mismas o más, precisamente el 52 y 47 por ciento, respectivamente.

En la mitad de las comunidades se realiza algún cultivo en laderas, lo cual aunque potencia la erosión cuando se trata de cultivos anuales realizados sin ninguna técnica especial, no deja de ser grato que sólo el cincuenta por ciento de las comunidades tengan necesidad de acudir a tales prácticas. Ahora bien, en el 47 por ciento de las comunidades existen tierras pantanosas o chaguites, aunque en un porcentaje bastante elevado es posible el avenamiento, con ello tales tierras podrían incorporarse a la actividad productiva.

Finalmente, siguiendo un orden de gravedad descendente, tenemos que sólo el 36 por ciento de las comunidades informan la existencia de agua contaminada, y un 22 por ciento, la presencia de cárcavas o deslaves pronunciados. En cuanto a la baja contaminación del agua no se crea que la respuesta se origina por la ignorancia o el desconocimiento de tal problemática, ya que el estudio de la calidad del agua ha sido una preocupación muy generalizada en estas comunidades, gracias al apoyo de algunos organismos no gubernamentales. El relativamente bajo nivel de cárcavas seguramente se pueda explicar por la topografía del terreno, la cual incide en la poca presencia de cultivos en laderas.

Pero el Cuadro 9, además de la información referida a los problemas y programas tendientes a contrarrestarlos, nos ofrece también información relativa a la capacitación de los productores agrícolas comunitarios, así tenemos que en el 83 por ciento de las comunidades se han impartido cursos de capacitación técnica, los cuales seguramente tengan relación con sus prácticas agrícolas. En cuanto a la educación ambientalista, ésta apenas ha cubierto al 54 por ciento de las comunidades, situación que quizá explique, en parte, el nivel incipiente de la agricultura orgánica.

\section{Otras actividades existentes en las comuni-} dades además de las agrícolas

Si bien son comunidades rurales, como lo he- 
mos señalado previamente, ello no significa que sus pobladores no realicen otras actividades diferentes de las agricolas y/o pecuarias. En 86 de las $100 \mathrm{co-}$ munidades manifestaron que tenían ganado vacuno, hecho que además de mejorar su dieta diaria constituye una fuente adicional de empleo e ingresos. También en sus huertos caseros, como lo veremos en su momento, realizan otras actividades, como la crianza de aves, cerdos y cabros. Por ahora centraremos nuestra atención en las actividades no agropecuarias, ya que éstas podrían llegar a ser fuente importante de empleo e ingresos si se desarrollaran, lo cual nos está indicando que aquí existe un ámbito que es preciso apoyar técnica y financieramente.

En el Cuadro 10 observamos que en 81 comunidades existe, al menos, una tienda pequeña; en 24 comunidades se dedican a la actividad del transporte $^{1}$, y en 23 comunidades existen actividades de confección. Igualmente se encuentran otras labores, como zapatería, carpintería, artesanías, hojalatería y comedores, aunque en un menor número de comunidades.

\begin{tabular}{lcll}
\multicolumn{4}{c}{$\begin{array}{c}\text { Cuadro } 10 \\
\text { Actividades no agropecuarias } \\
\text { en las comunidades }\end{array}$} \\
\hline \multicolumn{4}{c}{ Número de comunidades } \\
\hline Confección & 23 & Hojalatería & 18 \\
Zapatería & 10 & Tiendas & $\mathbf{8 1}$ \\
Carpintería & 20 & Comedores & 17 \\
Artesanía & 12 & Transporte & 24 \\
\hline
\end{tabular}

Parece claro que todas estas actividades, a excepción de los pequeños comercios, no son típicas de los asentamientos rurales, y de alguna manera muestran la metamorfosis entre estos representantes del Desarrollo Económico Comunitario (DEC). En algunos casos, estas habilidades y otras más fueron transmitidas a esta población durante el tiempo que pasaron en los refugios durante los años de la guerra, ya sea en el país o el extranjero. En otros, han sido sus acompañantes de las ONG's quienes han promovido la enseñanza de tales actividades, así como el ulterior montaje de un determinado proyecto, facilitando, por supuesto, los correspondientes recursos financieros.

\section{El empleo en las comunidades}

Toda esta realidad que estamos analizando se presenta como una estrategia de desarrollo altemativo, en la que las comunidades organizadas se caracterizan porque su población, antes que pedir o exigir, propone estructuras económicas organizadas a fin de generar empleo e ingresos.

Si bien ésta es la propuesta, no es menos cierto que aún no logran contar con empleo permanente para todos los integrantes de la comunidad debido, entre otras, a las razones siguientes: primero, porque aun teniendo capacidad o habilidades técnicas no pueden establecer nuevas empresas por falta de recursos financieros; segundo, porque la reciente capacitación y el abandono de las actividades agrícolas generan una mayor oferta de fuerza de trabajo desempleada; tercero, porque la capacitación de las mujeres contribuye a que éstas también demanden puestos de trabajo; cuarto, dado que son comunidades bastante nuevas, los excedentes aún no se presentan $y$, por tanto, tampoco los procesos de reinversión que posibilitarían la generación de nuevos puestos de trabajo. Ante tal situación, no es extraño que en las comunidades las oportunidades de empleo sean insuficientes.

\section{Cuadro 11}

Las oportunidades de empleo

\begin{tabular}{lr}
\hline Suficientes & 4 \\
Insuficientes & 93 \\
No contestaron & 3 \\
\hline Total & 100 \\
\hline
\end{tabular}

Sin embargo, no deja de ser altamente satisfactorio que, en por lo menos 4 comunidades, nos hayan manifestado que las oportunidades de empleo son suficientes, ya que son muy pocos los lugares, a nivel nacional, donde pudiera decirse algo igual. Por otra parte, el segundo y tercer puntos señalados supra se vuelven mucho más comprensibles cuando nos ocupamos de averiguar cuáles son los principales oficios de hombres y mujeres en las comunidades. Tal información se presenta en los Cuadros 12 y 13 para hombres y mujeres, respectivamente.

1 Esta actividad, debido a que requiere de una inversión bastante elevada, no puede ser de nadie considerado de manera individual sino que generalmente es propiedad de la comunidad. Lo mismo ocurre con otras actividades semejantes. 
Cuadro 12

Principales oficios en las distintas comunidades (Hombres)

\begin{tabular}{lrlr}
\hline Oficios & $\%$ & Oficios & $\%$ \\
\hline Agricultores & 100 & Panaderos & 29 \\
Albañiles & 65 & Zapateros & 26 \\
Carpinteros & 55 & Paraveterinarios & 16 \\
Motoristas & 51 & Mecánicos & 15 \\
Promotores & 50 & Veterinarios & 12 \\
Sastres & 44 & Obra de banco & 11 \\
Comerciantes & 35 & Agrónomos & 7 \\
Maestros & 29 & Para-agrónomos & 7 \\
\hline
\end{tabular}

Como era de esperar, en la totalidad de las comunidades existen personas que se dedican a la agricultura; sin embargo, ya no es tan obvia la cantidad de comunidades en las cuales existen albañiles, carpinteros, motoristas, promotores, maestros panaderos y zapateros. $Y$, ciertamente, resulta inesperada la presencia de paraveterinarios, mecánicos, veterinarios, mecánicos de banco, agrónomos y para-agrónomos. Esto se hace más evidente cuando, a excepción de los oficios domésticos, la costura y el comercio, encontramos mujeres aptas para trabajar como parteras, promotoras, profesoras, panaderas, enfermeras, alfareras y tejedoras (ver Cuadro 13).

Cuadro 13

Principales oficios en las distintas comunidades (Mujeres)

\begin{tabular}{lllr}
\hline Oficios & $\%$ & Oficios & $\%$ \\
\hline Oficios domésticos & 99 & Comerciantes & 28 \\
Costureras & 69 & Panaderas & 26 \\
Parteras & 57 & Enfermeras & 17 \\
Promotoras & 46 & Alfareras & 13 \\
Profesoras & 37 & Tejedoras & 8 \\
\hline
\end{tabular}

Ahora bien, los cuatro últimos cuadros (excepto el 11) nos presentan más que un problema, las enormes potencialidades que tienen las comunidades al poseer mano de obra calificada en una diversidad de actividades, ya sea para generar productos mercantiles, prestar servicios útiles y necesarios, o bien, para continuar organizando y capacitando a la fuerza de trabajo, sin necesidad de recurrir a cuadros técnicos externos a la comunidad, los cuales se presentan no sólo reacios a vivir en las comunida- des, sino que desconocen la realidad comunitaria y están poco interesados en la misma.

\section{Los ingresos familiares}

De toda la información obtenida ésta es la que consideramos menos confiable, la razón radica en lo siguiente: primero, las personas son reacias a informar acerca de sus ingresos; segundo, cuando se animan a hacerlo, es bastante difícil que consideren los ingresos monetarios y los no monetarios y, finalmente, no disponíamos de espacio para utilizar mecanismos indirectos que nos posibilitaran obtener toda la información. Téngase en cuenta que el rubro de los ingresos constituía tan sólo uno más entre los muchísimos rubros que contenía el instrumento. Aclarado lo anterior, veamos la información presentada en la Figura 2.

\section{Figura 2}

Promedio de ingreso familiar mensual

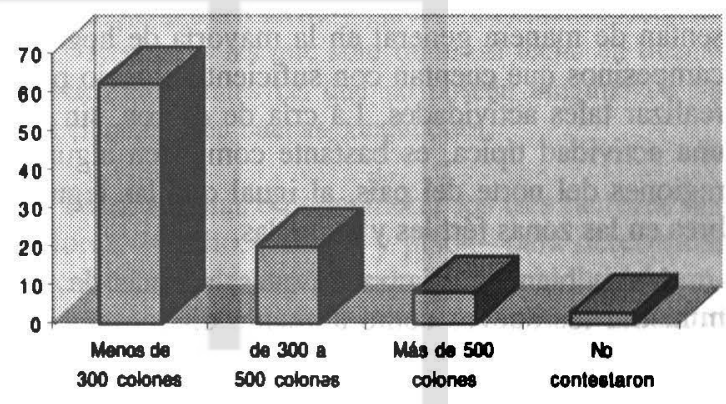

Tales ingresos no sólo son bajos sino que resultan insuficientes para satisfacer sus necesidades materiales. Aunque si consideramos que no pagan vivienda ni agua, como tampoco otra serie de servicios y que adicionalmente producen en sus huertos familiares parte de los alimentos que consumen, no tendríamos mayor problema en considerar que sus condiciones de vida, tal como lo hemos observado, son mejores que las de los campesinos del resto del país.

En virtud de que todas las viviendas de las comunidades poseen solares en donde realizan actividades económicas familiares, como la crianza de animales y la producción de algunos vegetales, lo cual contribuye a satisfacer sus necesidades materiales, presentaremos tal información antes de mostrar las fuentes de los ingresos monetarios en las comunidades. Hay que aclarar que cuando se hace referencia a los ingresos, inmediatamente se piensa 
en ingresos monetarios donados o recibidos por realizar algún trabajo; pero la actividad económica que se realiza en los solares de las viviendas, como se muestra en el Cuadro 16, es de suma importancia para comprender la estrategia de vida en dichas comunidades.

Cuadro 14

Uso de los solares de las viviendas

\begin{tabular}{lccccc}
\hline & Más del 50\% & $50 \%$ & Menos del 50\% & No crían & No contesta \\
\hline Crianza de aves & 78 & 9 & 12 & 1 & - \\
Crianza de cerdos & 25 & 12 & 52 & 11 & - \\
Crianza de cabros & 0 & 0 & 41 & 57 & 2 \\
Cultivo árboles frutales & 36 & 16 & 37 & 11 & - \\
Cultivo legumbres y hortalizas & 65 & 5 & 1 & 28 & 1 \\
\hline
\end{tabular}

Las aves y hortalizas se presentan como actividades generalizadas en los hogares de las comunidades, seguidos de la crianza de cerdos y el cultivo de árboles frutales, ubicándose en el último lugar de importancia la crianza de cabros. Los rubros anteriores, excluidos los caprinos y las hortalizas, se presentan de manera general en la mayoría de hogares campesinos que cuentan con suficiente espacio para realizar tales actividades. La cría de cabros, sin ser una actividad típica, es bastante común en algunas regiones del norte del país, al igual que las legumbres en las zonas fértiles y húmedas.

Ahora bien, la crianza de aves, además de suministrar los huevos como alimento diario, también ofrece la posibilidad de alimentarse con las gallinas o los gallos que ya no están en su edad más productiva. Por otra parte, la crianza de dichos animales constituye una forma de ahorro, ya que es posible venderlos fácilmente cuando se requiera de dinero.

Los cerdos y caprinos, por su lado, conforman la estrategia de ahorro de mediano plazo, más o menos un año, ya que transcurrido este tiempo es posible venderlos y obtener alguna cantidad no despreciable de dinero claramente superior a la que se obtiene de vender gallinas o gallos. También los cerdos y los cabros constituyen parte de la reserva de recursos para las emergencias, cualquiera que sea la naturaleza de éstas. Adicionalmente, de las cabras es posible obtener leche, la cual es muy apreciada por los campesinos ya que se le atribuyen cualidades altamente nutritivas. Pero de la misma forma también pueden obtener algunos ingresos diarios de la venta de la leche.

Los frutales como las legumbres son fuente de alimentos e ingresos complementarios aunque, en general, las familias campesinas no se ocupen de contabilizarlos, ni a ellos ni a los rubros considerados con anterioridad, pero en realidad forman parte de sus ingresos familiares mensuales, to cual nos llevaba a sostener que los ingresos familiares informados en las comunidades están subestimados.

Por otra parte, las fuentes de ingresos de los campesinos pobres generalmente no se reducen a su propio trabajo. En la actualidad, las remesas ocupan un lugar muy importante dentro de los ingresos de las familias rurales en el país. A fin de establecer el carácter típico o atípico de las comunidades, desde la perspectiva de las remesas, exploramos acerca de sus posibles fuentes de ingresos. Los resultados se presentan en el Cuadro 15.

Cuadro 15

Principales fuentes de ingresos

\begin{tabular}{lrlr}
\hline Trabajo en comunidad & 57 & Trabajo fuera de la comunidad & 2 \\
Trabajo en y fuera de la comunidad & 15 & Trabajo en la comunidad y AFN & 1 \\
Trabajo en comunidad y AFE & 7 & Trabajo fuera de la comunidad y AFE & 2 \\
No contestaron & 16 & & Total \\
\hline
\end{tabular}

AFE = Ayuda familiar del exterior AFN = Ayuda familiar nacional 
Como se puede apreciar en el Cuadro 15, en las comunidades es poco significativa la ayuda familiar que se recibe fuera de la comunidad, son apenas 10 comunidades las perciben algún tipo de ayuda, 9 las que reciben ayuda familiar del exterior y una que tiene ayuda familiar nacional. En cerca del 60 por ciento de las comunidades las familias viven de su trabajo en la comunidad y sólo 17 tienen que acudir todavía a trabajar fuera de ella, lo cual ha sido y es una práctica generalizada entre las familias rurales.

La estrategia tradicional de supervivencia campesina ha sido, precisamente, el cultivo de granos básicos en minifundios para el autoconsumo y venta de fuerza de trabajo en las plantaciones de café y/ o caña de azúcar, a fin de conseguir ingresos extras para poder vivir. El que esta práctica se esté modificando nos indica que, posiblemente, ya no se requiera acudir a la venta de la fuerza de trabajo en las plantaciones para satisfacer sus necesidades, lo cual puede entenderse de manera positiva en el sentido de que la nueva estrategia de vida comienza a funcionar, que el desarrollo económico comunitario está convirtiéndose en una realidad.

En la información recabada, sólo en 9 comunidades de las 100 estudiadas existen familias cuya fuente principal de ingresos está fuera de la comunidad o lo es de manera combinada.

\section{Las condiciones de vida en las comunidades}

Hasta ahora nos hemos ocupado por estudiar las condiciones de trabajo de las familias comunitarias, inclusive, de sus ingresos. Pero, ¿en qué se traducen todos esos esfuerzos en la vida de la comunidad?, ¿cuáles son las condiciones de sus viviendas, o las condiciones de que disponen para lograr educación y preservar la salud? De estos aspectos, que de alguna forma son los objetivos materiales comunes a cualquier familia, vamos a ocupamos ahora. Inicaremos con la vivienda.

\subsection{La vivienda y los servicios básicos}

Si excluimos las viviendas que se encuentran en malas condiciones -incluyendo las distintas combinaciones de las malas- de tal manera que nos quedemos sólo con las tres primeras filas de ambas columnas, encontramos que, al menos, el 56 por ciento de las viviendas se encuentran en condiciones que van de regulares a excelentes. Tal resultado parece bastante halagüeño dadas las tradicionales pésimas condiciones de la vivienda en el campo. Por otro lado, no parece ser una cifra exagerada si tenemos en cuenta que son muchísimas las comunidades en las que se observa la construcción de viviendas o viviendas nuevas ya terminadas.

Condiciones de las viviendas en las comunida-
des*

(En porcentajes)

- Excelentes son aquellas viviendas que poseen el techo, las paredes y el piso en buenas condiciones. Buenas las que poseen techo y paredes en buenas condiciones. Regulares las que sólo tienen el techo en buenas condiciones. Malas las que no poseen ninguno de los tres elementos en buenas condiciones.

Pero, además de considerar los tres factores anteriores - techo, paredes y piso- para determinar la condición de la vivienda hemos incluido también otros elementos, como la energía eléctrica, el agua, etc. Consideramos que nos dice más el estado de los tres factores anteriores que los materiales de construcción, ya que el hecho de que una pared sea de adobe, ladrillo, bloque o bahareque no nos especifica nada acerca de su estado, igual ocurre con el techo, que puede ser de teja, asbesto, fibrolit o lámina y su estado queda indeterminado.

Ahora bien, como queremos determinar las condiciones de vida, hubo necesidad de considerar otros factores como los servicios ya mencionados (ver Cuadro 17).

Los resultados muestran que en 43 comunidades, de las 100 estudiadas, existe servicio de energía eléctrica, aunque solamente en 7 todas las viviendas tengan el servicio; en 17, la mayoría; y en 19, sólo algunas viviendas. Sin embargo, al considerar que ya hay instalaciones, más temprano que tarde todas las viviendas de las 43 comunidades tendrán energía eléctrica. Al menos más temprano que las otras comunidades, en donde aún no existe ninguna infraestructura $o$ instalaciones eléctricas. 
Cuadro 17

Servicios en las viviendas

\begin{tabular}{lccccc}
\hline & Todas & Algunas & La mayoría & Ninguna & No contesta \\
\hline Tienen energía eléctrica & 7 & 19 & 17 & 56 & 1 \\
Disponen de agua potable & 19 & 17 & 11 & 53 & - \\
Poseen letrinas & 47 & 23 & 28 & 2 & - \\
Usan leña para cocinar & 79 & 4 & 17 & - & - \\
\hline
\end{tabular}

En cuanto al servicio de agua potable, la situación es un poco mejor a nivel general, ya que son 47 las comunidades que cuentan con el servicio, y 19 en donde todas las viviendas pueden gozar de este elemento.

Respecto a la letrinización, es bastante satisfactorio encontrar que solamente existen dos comunidades en donde las viviendas no poseen letrinas; en 23 , sólo algunas viviendas; en 28 , la mayoría, y en 47 , todas.

Estos dos elementos son de suma importancia para prevenir enfermedades infectocontagiosas, las cuales han sido padecidas de manera crónica por los habitantes rurales. En tal sentido, podemos sostener que las familias de estas comunidades gozan de mejores condiciones de vida que la generalidad de los habitantes rurales, lo cual resulta bastante grato de presentar.

Finalmente también investigamos sobre el uso de la leña y fue claro que en todas las comunidades la usan. Con todo, existen 21 comunidades en donde algunas viviendas ya no usan leña en sus cocinas, por supuesto que se trata de comunidades rurales con un avance significativo.

\subsection{Infraestructura y servicios sociales}

Además de la vivienda, es importante conocer los aspectos de educación, la preservación de la salud, así como también sobre los satisfactores espirituales. Para ello recopilamos información acerca de la infraestructura y los servicios sociales, la cual se presenta en el Cuadro 18.

Cuadro 18

Infraestructura y servicios sociales

\begin{tabular}{llll}
\hline & Sí & No & No contesta \\
\hline Existe escuela en la comunidad & 77 & 23 & - \\
La escuela es de la comunidad & 63 & 11 & 3 \\
La comunidad paga a los profesores & 13 & 62 & 2 \\
Existe clínica en la comunidad & 39 & 59 & 2 \\
Existe promotor de salud & 83 & 15 & 2 \\
Existe casa comunal o centro cultural & 82 & 18 & - \\
Existe iglesia o un lugar para el culto & 52 & 46 & 2 \\
\hline
\end{tabular}

La preocupación y el interés por la educación se observan en las comunidades en el hecho de que solamente 23 de las 100 estudiadas no tienen escuela, pero, sobre todo, en el novedoso fenómeno de que de esas 77 escuelas que existen en igual número de comunidades, 63 les pertenecen a ellas. Es decir, sus habitantes, con ayuda de agencias del exterior, han construido los edificios donde se educan sus hijos. Y por si esto fuese poco, en 13 escuelas de las 63 , la comunidad es la que le paga a los profesores.
Estos hechos bastante novedosos son los que animan y entusiasman a cualquier observador extemo de esta realidad. Pero además de la preocupación por la educación, como vemos en el Cuadro 18,39 comunidades cuentan con una clínica y 83 tienen, al menos, un promotor de salud. $Y$ decimos al menos, ya que algunas comunidades reciben la visita periódica de médicos e, inclusive, en la comunidad de Sisiguayo hay un médico que ha decidido unir su vida a la de estas tan promisorias personas. 
A fin de atender sus necesidades espirituales, en 82 comunidades tienen un local que funciona como casa comunal, o bien, como centro cultural. Pero si lo anterior pudiera resultar sorprendente, ocurre que en 52 de las 100 comunidades ya tienen iglesia o, en todo caso, un lugar para realizar sus prácticas religiosas, lo cual no deja de ser un poco desconcertante para un observador ajeno a la vida en comunidad, particularmente al conocer el cúmulo de necesidades que tienen que satisfacer con tan pocos recursos. Pero como muy bien se dice: no sólo de pan vive el hombre.

\subsection{Las ayudas que reciben las comunidades}

Cuando mencionamos ayudas, no nos referimos únicamente a las económicas, sino también a la ayuda técnica y científica que las comunidades necesitan para avanzar por la senda de su desarrollo. Valga aclarar que al hablar de desarrollo a secas o desarrollo económico, queremos expresar una condición tal en la cual las personas logran satisfacer en gran medida sus necesidades materiales y espirituales. Al hacer tal aseveración tenemos en cuenta el planteamiento de Manfred Max Neef sobre el desarrollo a escala humana, y aceptamos su enfoque acerca de que las necesidades humanas son relativamente estables, lo que varía son sus satisfactores.

\section{Cuadro 19}

Apoyos que reciben las comunidades

\begin{tabular}{lllll}
\hline Si & No $\begin{array}{c}\text { No } \\
\text { Contesta }\end{array}$ & Total \\
\hline
\end{tabular}

Se cuenta con personal

\begin{tabular}{l|cccc}
$\begin{array}{l}\text { técnico pagado } \\
\begin{array}{l}\text { Se cuenta con apoyo } \\
\text { del alguna ONG }\end{array}\end{array}$ & 16 & 83 & 1 & 100 \\
$\begin{array}{l}\text { Se cuenta con ayuda } \\
\text { del gobiemo }\end{array}$ & 59 & 40 & 1 & 100 \\
\hline
\end{tabular}

No es sorprendente que los apoyos técnicos pagados por la comunidad sean tan bajos, dado que se trata de comunidades pobres que buscan la senda del desarrollo, incluso, apenas $\mathbf{1 6}$ comunidades cuentan con recursos económicos para pagar a un técnico. Esta situación no debe interpretarse como falta de ayuda técnica, ya que las ONG's, entre otros apoyos, la proporcionan. En el momento de este estudio, las ONG's estaban presentes en 87 de las cien comunidades.

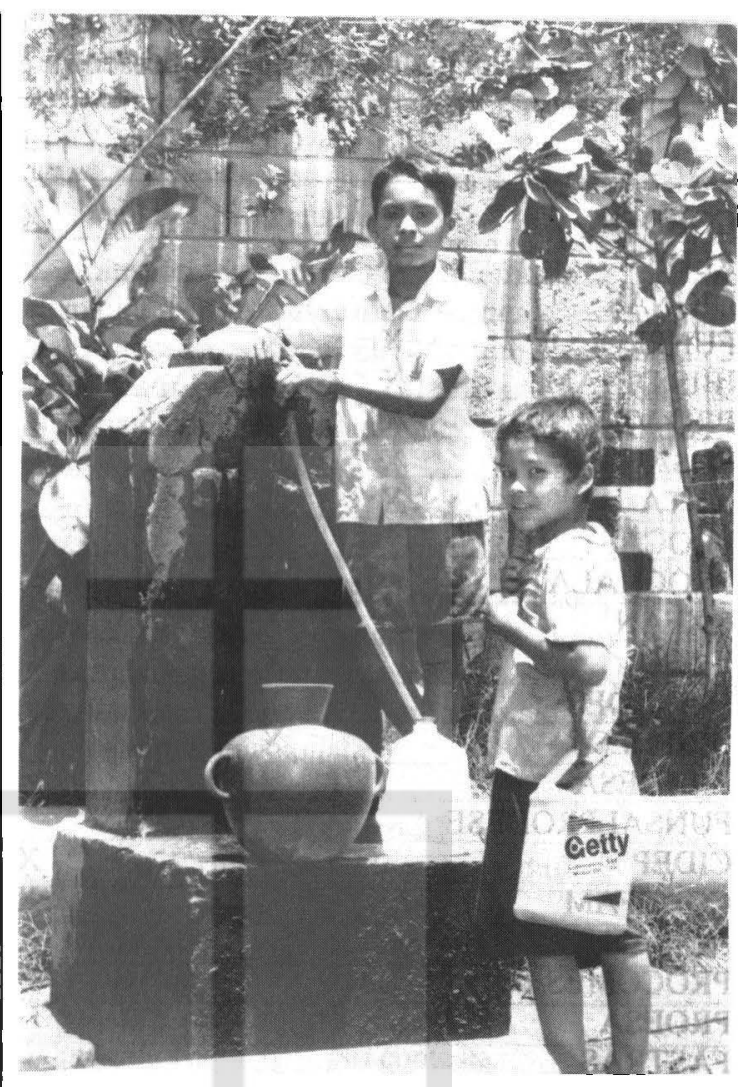

El apoyo de los organismos no gubernamentales son múltiples y variados, razón por la cual desempeñan una función de suma trascendencia en el desarrollo de las comunidades. Sin estas instituciones, seguramente no sería posible ni siquiera pensar en esta estrategia de desarrollo, al menos en su fase incipiente que es en la que se encuentra la mayoría de comunidades. Pero tampoco consideramos que siempre serán un factor imprescindible, al contrario, una buena ONG será aquella que acompaña a las comunidades sin reemplazar su protagonismo, que sabe reconocer que los sujetos son los habitantes de las comunidades y no los promotores de la ONG y que desde su primer contacto con la o las comunidades prepara su partida. Y es que lo más importante es asegurarse de que las comunidades van a caminar solas.

El listado de ONG's que presentamos en el Cuadro 20 no incluye a todas, y las que se mencionan trabajan en más departamentos de los que informamos; ello obedece a que fueron las ONG's que nos reportaron los habitantes de las comunidades consultadas. 
Cuadro 20

Principales ONG's y su presencia en las comunidades por departamento

\begin{tabular}{|c|c|c|c|c|c|c|c|c|c|c|}
\hline & $\mathrm{Ca}$ & Cha & Cus & LL & LP & Mo & SM & SS & SV & Usu \\
\hline CORDES & $\mathbf{X}$ & $\mathbf{X}$ & $\mathbf{X}$ & $\mathbf{X}$ & & & & $\mathbf{X}$ & $\mathbf{x}$ & \\
\hline REDES & $\mathbf{X}$ & & $\mathbf{X}$ & & & & & & & \\
\hline DIGNAS & $\mathbf{X}$ & & & & & & & & & \\
\hline FUNPROCOP & $\mathbf{X}$ & $\mathrm{x}$ & & & & & & & & \\
\hline IBIS DINAM. & $\mathbf{X}$ & & & & & & & & & \\
\hline PRO VIDA & $\mathbf{x}$ & & $\mathbf{X}$ & & & & & $\mathbf{X}$ & & \\
\hline FUSAI & $\mathrm{X}$ & & & & & & & & & \\
\hline ANTA & $\mathrm{X}$ & $\mathbf{x}$ & & & & & & & & \\
\hline PROCAP & & $\mathrm{X}$ & & & & & & & & \\
\hline PROCHALATE & & $\mathbf{X}$ & & & & & & & & \\
\hline OXFAN & & $\mathbf{X}$ & & & & & & & & \\
\hline F 16 & & $\mathbf{X}$ & & & & & & & & \\
\hline FUCRIDES & & $\mathbf{X}$ & & & & & & $\mathbf{X}$ & & \\
\hline CRIPDES & & $\mathrm{X}$ & & $\mathrm{X}$ & & & & $\mathbf{X}$ & & \\
\hline FUNDESA & & & $\mathrm{X}$ & & & & & $\mathrm{X}$ & $\mathbf{X}$ & $\mathbf{X}$ \\
\hline FUNSALPRODESE & & & $\mathbf{X}$ & & & & $\mathbf{X}$ & $\mathrm{X}$ & & \\
\hline CIDEP & & & & $\mathbf{X}$ & & & & & & \\
\hline CODEFAM & & & & $\mathbf{X}$ & & & & & & \\
\hline ACISAN & & & & $\mathbf{X}$ & & & & & & \\
\hline PROCOMES & & & & & $\mathbf{X}$ & & & & & \\
\hline PिOESA & & & & & & $\mathrm{X}$ & & $\mathbf{X}$ & & $\mathbf{X}$ \\
\hline FASTRAS & & & & & & $\mathbf{X}$ & $\mathbf{X}$ & & & \\
\hline SOGEMA & & & & & & $\mathrm{X}$ & & & & \\
\hline FUNDASAL & & & & & & $\mathrm{X}$ & & $\mathrm{X}$ & & \\
\hline FUNDAES & & & & & & & $\mathrm{X}$ & & & $\mathbf{X}$ \\
\hline CODEUSMI & & & & & & & $\mathbf{X}$ & & & $\mathbf{X}$ \\
\hline CODECOSTA & & & & & & & $\mathbf{X}$ & & & $\mathbf{X}$ \\
\hline FUNSAL & & & & & & & $\mathbf{X}$ & & & \\
\hline ARZOBISPADO & & & & & & & & $\mathbf{X}$ & & \\
\hline$\overline{\mathrm{CARE}}$ & 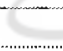 & & & & & & & & $\mathbf{x}$ & $\mathbf{x}$ \\
\hline CEDRO & & & & & & & & & $\mathbf{X}$ & \\
\hline ASDI & & & & & & & & & $\mathbf{X}$ & $\mathbf{X}$ \\
\hline S. J. & & & & & & & & & & $\mathbf{X}$ \\
\hline U.E. & & & & & & & & & & $\mathbf{X}$ \\
\hline ITAMA & & & & & & & 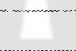 & & & $\mathbf{X}$ \\
\hline PROCAMPO & & & & & & & & & & $\mathbf{X}$ \\
\hline
\end{tabular}

Las actividades que estas instituciones apoyan en las comunidades tienen relación con lo financiero - hablamos de donaciones para una diversidad de programas. Así como también contemplan proyectos de crédito, comercialización, formación y capacitación cooperativista, medio ambiente, desarrollo local, prácticas agrícolas, género, agua, energía eléctrica, salud, educación, vivienda, etc. El menú que ofrecen estos organismos es tan variado como las necesidades de las comunidades, desafortunadamente el aporte que reciben las comunidades es insuficiente $y$, además, nos parece que tiene una distribución desigual. Existen comunidades que reciben mucha ayuda mientras otras 
no reciben nada, aunque las necesidades sean iguales.

Adicionalmente, la presencia de las ONG's en los departamentos depende del número de comunidades que exista en los mismos, aunque son más privilegiados aquellos que están más próximos a la capital. Y es que si bien la mayoría de personas que trabajan con las ONG's de una u otra forma son personas con algún compromiso solidario con los pobres y marginados, hay quienes también les anima más el afán de servirse a sí mismos que a los demás.

Entre las ONG's que presentamos en el Cuadro 20 existen algunas especializadas en tareas muy precisas, así tenemos, por ejemplo, a Fundasal, que se dedica exclusivamente a la construcción de vivienda bajo el sistema de ayuda mutua; las Dignas, sólo a actividades de la mujer; Funprocop, dedicada al fomento cooperativo; y otras cuyo trabajo va más encaminado en la línea de propiciar el desarrollo por lo que operan en varias actividades tanto económicas como sociales. Sin embargo, el énfasis radica en la organización para la realización de actividades económicas, tales son, por ejemplo, Cordes, Funsalprodese, Asdi, Redes, Codeusmi. También encontramos a las vinculadas con los derechos humanos, como Codefan; con los desmovilizados del FMLN, F 16 (Fundación 16 de enero); y con las actividades gremiales, como Anta, etc.

Por otra parte, el apoyo que reciben del gobierno, aunque no es generalizado, está asociado con las dependencias que se ocupan de la educación, la salud, el agua, la energía eléctrica, la agricultura, el desarrollo local, etc. Así se reportan instituciones, como Centa, Mined, FIS, SRN, Isdem, MAG, BFA, Fonavipo y algún programa como Educo.

$Y$ aunque 59 de las 100 comunidades informen apoyo del gobierno, no sólo es lamentable que no esté en todas las comunidades como es su obligación, al menos en materia de educación y salud, sino que el tipo de ayuda que presta no deja de ser asistencialista y poco o nada propiciadora del desarrollo comunitario. Ya ha transcurrido bastante tiempo para entender que más que recibir pescado, los pueblos deben aprender a pescar, y ni siquiera este planteamiento asume el gobierno hoy cuan- do las nuevas prácticas del desarrollo económico comunitario están demostrando que no basta tampoco con que se les enseñe sólo a pescar.

\section{Los problemas y los recursos económicos reales y potenciales}

Anteriormente hacíamos referencia a la problemática relacionada con los ingresos y el empleo, ahora se nos presenta otro tipo de problemas, como son aquellos relacionados con el financiamiento, la generación y el destino del excedente, etc.

También nos interesa determinar con qué otros recursos cuentan las comunidades además de la tieпra. Pero sobre todo importa establecer sus potencialidades, dado que la tendencia que presentan las comunidades es a crecer, no sólo a causa de la incorporación de nuevos miembros, sino debido al crecimiento poblacional.

\section{Cuadro 21}

Evolución de la comunidad

\begin{tabular}{clr} 
¿Cuál ha sido & Ha crecido & 69 \\
la evolución & Ha disminuido & 8 \\
de la & Se mantiene & 19 \\
comunidad? & No contesta & 4 \\
\hline
\end{tabular}

Como se observa en el Cuadro 21, casi un 70 por ciento de las comunidades han tenido una tendencia a crecer; alrededor de un 20 por ciento se ha mantenido y sólo un 8 por ciento ha disminuido. Reducciones que a menudo han respondido a reubicaciones de la población en otras comunidades organizadas $\mathrm{e}$, inclusive, a desgajamientos que se han traducido en la fundación de una nueva comunidad más que a retiros de éstas y, en consecuencia, de la vida comunitaria.

\subsection{El financiamiento de las comunidades}

Pero bien, en-
El apoyo de los organismos no gubernamentales son múltiples y variados, razón por la cual desempeñan una función de suma trascendencia en el desarrollo de las comunidades. trando a la temática que buscábamos estudiar encontramos que la principal fuente de los recursos financieros se encuentra en el crédito, tal como se puede ver en el Cuadro 22. 
Cuadro 22

Origen de los recursos financieros (\%)

\begin{tabular}{clr}
\hline ¿Cuál es & Propios & 17 \\
el origen & Prestados & 48 \\
de los recursos & Propios y prestados & 27 \\
financieros? & Prestados y donados & 4 \\
& No contesta & 4 \\
\hline
\end{tabular}

Deseamos destacar que aunque existe cierto porcentaje, el 17 por ciento, que opera con recursos propios, el resto de alguna manera está vinculado con el crédito, razón por la cual es importante estudiar la forma de obtención del mismo, así como los costos del crédito. Esta información la presentamos en los cuadros que se citan más adelante.

\section{Cuadro 23}

Apreciación acerca de los costos financieros (\%)

\begin{tabular}{clr}
\hline ¿Cómo & Altos & 45 \\
consideran & Bajos & 8 \\
los intereses? & Aceptables & 24 \\
\hline & Total & 77 \\
\hline
\end{tabular}

Aunque el 31 por ciento de los usuarios consideran que los intereses son aceptables, el 58 por ciento los estima como altos y sólo el 10 por ciento, como bajos. Claro, como estas comunidades no operan con la banca comercial, en su gran mayoría, sino con ONG's, realmente tienen mucho sentido las tres apreciaciones, ya que no se trata de opiniones subjetivas, sino que obedecen a las fuentes distintas de financiamiento. Pero, aún así, la mayoría considera que las tasas son altas, y esto quizá tiene que ver con la baja rentabilidad de las actividades agrícolas o también con la forma y el momento de obtención del crédito. Sobre ello versan los cuadros que se citan adelante.

\section{Cuadro 24}

Forma de obtención de créditos (\%)

\begin{tabular}{clc}
\hline ¿Cuál es la & Colectiva & 11 \\
forma de & Individual & 49. \\
acceso a & Combinada & 19 \\
los créditos? & No contestaron & 21 \\
\hline
\end{tabular}

Es obvio que cuando se accede a cualquier mercado, inclusive el del dinero, es posible obtener mejores precios de manera colectiva que de manera individual y, para nuestra sorpresa, en las comunidades la mayoría de los créditos se obtienen de manera individual: el 49 por ciento lo hace así contra un 11 por ciento que lo obtiene de manera colectiva. La razón seguramente se deba a la responsabilidad para pagar, que parece mayor cuando la obligación es individual. El número elevado de quienes no contestan se explica porque no usan dinero prestado.

\section{Cuadro 25}

Oportunidad en la obtención de los créditos (\%)

\begin{tabular}{c|ll}
\hline ¿Cómo & Oportunamente & 36 \\
se obtienen & Tarde & 23 \\
los créditos? & Con tiempo & 10 \\
& No contestaron & 31 \\
\hline
\end{tabular}

Finalmente pensamos que no existe problema en cuanto a la oportunidad para la obtención de créditos, ya que quienes los obtienen lo hacen de manera oportuna, de manera que este elemento no estaría incidiendo a fin de considerar a los intereses como muy altos, ya que el momento de su obtención no es causa de bajos rendimientos.

\subsection{La rentabilidad comunitaria}

¿Y cuál es la rentabilidad de las familias o de las comunidades? Aunque la rentabilidad comunitaria debe ser vista primero como una rentabilidad social y sólo secundariamente como una rentabilidad financiera, la información que presentaremos está referida a la segunda.

Rentabilidad social es aquella que se presenta, primero, cuando se reporta una situación de igualdad entre los ingresos y los gastos, pero que ha generado empleo e ingresos para los trabajadores comunitarios que de otra manera no hubieran podido obtener. Segundo, cuando gracias a la vida en comunidad se satisfacen una serie de necesidades sociales que sería imposible de cubrir de otra forma. Y, tercero, hay rentabilidad social cuando gracias a la comunidad se tiene acceso a satisfactores no materiales, como seguridad, libertad, autoestima, participación, etc. Pero bien, la información recabada acerca de la rentabilidad se presenta en el Cuadro 26. 
Cuadro 26

Rentabilidad en las comunidades (\%)

\begin{tabular}{clr}
\hline ¿Cuál ha sido & Utilidades & 21 \\
su situación & Pérdidas & 31 \\
financiera & Ni ganado ni perdido & 46 \\
el último año? & No contestaron & 2
\end{tabular}

En primer lugar, casi la mitad de las comunidades gozan de rentabilidad social; una tercera parte sufre pérdidas, lo cual es muy grave ya que no hay posibilidad ni siquiera de reproducción simple, al operar con pérdidas se camina como por una pendiente hacia la extinción. El hecho de que una tercera parte de las comunidades presenten tal situación exige de algunas reflexiones propositivas.

También encontramos que una quinta parte de las comunidades que obtienen utilidades opera con excedentes. Con ello podemos afirmar que cerca del 70 por ciento de las comunidades son rentables social y financieramente. En consecuencia, podría sostenerse que el Desarrollo Económico Comunitario como estrategia alternativa de desarrollo debe ser considerada con seriedad como una opción de desarrollo.

Pero antes de expresar todo nuestro entusiasmo, es necesario concluir este apartado determinando cuál es el destino que tiene el excedente obtenido, aunque dada la situación de insuficiencia en los puestos de trabajo, como lo veíamos con anterioridad, éste debería ser el uso principal del excedente, ya que de esa manera se incrementaría la actividad económica y, en consecuencia, los puestos de trabajo. Pero la realidad con toda su complejidad es la que se presenta en el Cuadro 27.

\section{Cuadro 27}

Destino de las utilidades (\%)

\begin{tabular}{llr}
\hline ¿Cuál es & Distribuido & 4.7 \\
el uso & Pago deudas & 4.7 \\
o destino & Reinversión & 71.4 \\
del excedente? & Las tres anteriores & 19.0 \\
\hline
\end{tabular}

Teóricamente, éstos son los resultados que se esperarian. El excedente en elevada proporción se destina a la reinversión; casi un 5 por ciento se distribuye entre los trabajadores y otro tanto para pagar deudas acumuladas.

\subsection{Recursos materiales disponibles}

A fin de explorar las posibilidades que estas comunidades tienen de avanzar por la senda del desarrollo, es necesario conocer los factores de la producción existentes en las mismas. Ellas cuentan con tierra y fuerza de trabajo abundante - ésta última tiene alguna calificación. También hemos considerado las técnicas agrícolas empleadas y los recursos financieros que usan. Ahora queremos determinar cuál es la condición de otros factores de la producción, como ganado, maquinaria y equipos agrícolas, capacidad e infraestructura de riego e, inclusive, explorar si existe alguna tierra agrícola que no esté siendo utilizada. Con tal fin se presenta la información contenida en el Cuadro 28.

\section{Cuadro 28}

Recursos económicos materiales

\begin{tabular}{lccc}
\hline & Sí & No & No contesta \\
\hline $\begin{array}{l}\text { Tienen ganado } \\
\begin{array}{l}\text { Tienen maquinaria } \\
\text { y equipo }\end{array}\end{array}$ & 86 & 11 & 3 \\
$\begin{array}{l}\text { Tienen infraestructura } \\
\text { de riego }\end{array}$ & 18 & 75 & 7 \\
$\begin{array}{l}\text { Existe capacidad de } \\
\text { riego no usada }\end{array}$ & 32 & 54 & 14 \\
$\begin{array}{l}\text { Existe tierra cultivable } \\
\text { ociosa }\end{array}$ & 53 & 43 & 4 \\
$\begin{array}{l}\text { La tierra de que disponen } \\
\text { es suficiente }\end{array}$ & 28 & 64 & 8 \\
\hline
\end{tabular}

Con anterioridad señalamos que, como parte de sus estrategias de ahorro, las comunidades poseen en sus huertos caseros algunos animales, como aves, cerdos y cabras. Pero además de esas especies menores también poseen ganado vacuno, ya sea para la obtención de leche o carne. La ganadería es una actividad de suma importancia dentro de las actividades económicas agropecuarias, razón por la cual resulta grato encontrar que en 86 por ciento de las comunidades cuentan con ella.

Por otra parte, para conseguir una mejor producción agropecuaria generalmente es conveniente auxiliarse de maquinaria y equipo agrícolas, ya que éstos posibilitan el incremento de la productividad del trabajo. Cabe señalar que éstos requieren de ciertas inversiones de capital, a las que no siempre 
les es posible tener acceso a las comunidades, por lo que seguramente sólo 35 de las 100 comunidades estudiadas disponen de tales medios de producción.

Otro factor que incide en la productividad anual del trabajo es el riego, por ello se investigó si existía capacidad de riego así como infraestructura instalada, ya que sin ella no es posible aprovechar el agua. Los resultados obtenidos nos indican que en $18 \mathrm{co-}$ munidades se cuenta con infraestructura para el riego y que en 32 existe esta capacidad pero no se usa, en consecuencia, podemos afirmar que la mitad de las comunidades podrían hacer uso de este sistema con fines agrícolas, ganaderos o piscícolas.

\subsection{Recursos económicos potenciales}

La profundización de esta temática nos conduce a explorar aquellos recursos económicos poten- ciales que están asociados o que pudieran explotarse si se aprovechan los recursos hídricos existentes. Todo ello se vuelve muy importante porque el conocimiento de los mismos es clave para la elaboración de cualquier estrategia de desarrollo a mediano y largo plazo.

Así tenemos que la capacidad hídrica disponible ha sido explorada en los tres rubros antes señalados - agricultura, ganadería y piscicultura- y se nos informó que en 26 comunidades podrían cultivar granos bajo riego y en 30 , hortalizas. Hacerlo significaría incrementar las oportunidades de trabajo durante la estación seca del año, que es precisamente la época durante la cual son más escasas las oportunidades de laborar. Pero no sólo se incrementaría el empleo y consecuentemente el ingreso de las familias, sino que aumentaría la cantidad de bienes producidos en las comunidades, ya sea para el consumo o la venta.

Cuadro 29

Recursos económicos potenciales, estudios y proyectos

\begin{tabular}{lllll}
\hline & & Sí & No & No contesta \\
\hline \multirow{2}{*}{ Existen } & Cultivo de granos & 26 & 74 & - \\
recursos & Cultivo de hortalizas & 30 & 70 & - \\
hídricos & Cultivo de pasto & 19 & 81 & - \\
para ....? & Crianza de camarón & 15 & 85 & - \\
& Crianza de peces & 13 & 87 & - \\
Cuentan con estudios y proyectos & & & 15 \\
Cuentan con proyectos en gestión & 20 & 65 & 9 \\
\hline
\end{tabular}

Adicionalmente en 19 comunidades tienen capacidad para cultivar pasto bajo riego, tal hecho posibilita la ampliación del hato ganadero y, además, la disminución de los costos de producción. Lo anterior se traduce en la posibilidad de incrementar el excedente económico, además de los otros factores previamente señalados. Pero también existe capacidad hídrica para incursionar en la piscicultura con la crianza de camarón y pescado en 15 y 13 comunidades, respectivamente. Con tales actividades no sólo se abre la posibilidad de variar y mejorar la dieta alimenticia, sino de generar nuevos puestos de trabajo e ingresos.

Lo más interesante de esta situación es que no se trata de posibilidades teóricas. En realidad, las comunidades cuentan con estudios y proyectos para realizar éstas y otras actividades, al menos en una quinta parte de las comunidades, y en dos quintas partes ya han gestionado recursos para implementar nuevos proyectos.

Como el futuro de las comunidades depende de que logren desarrollar sus actividades económicas, hay que señalar que en, primer lugar, dado su alto grado de iniciativas, propuestas y búsquedas en materia económica, para la mayoría de comunidades el futuro se presenta como muy promisorio. En segundo lugar, si tenemos en cuenta lo mucho que han logrado en tan poco tiempo, la comunidad más vieja tiene apenas 10 años, no dudamos en prever que se encaminan hacia la consecución de mejores condicio- 
nes de vida y trabajo. $Y$, en tercer lugar, como se afirma y sostiene que el desarrollo agropecuario presupone la diversificación del mismo, se busca detectar qué posibilidades existen en las comunidades de iniciar nuevas actividades, además de las asociadas al riego. Pero como no se trata de pro- mover cualquier cosa por el solo hecho de que sea novedosa, se preguntó sobre la posibilidad de nuevos proyectos para los que se cuenta con tierra apta, agua suficiente y/o experiencia en la actividad por emprender. Los resultados aparecen en el Cuadro 30.

Cuadro 30

Proyectos que podrían implementarse en las comunidades*

\begin{tabular}{llllll}
\hline Frutales varios & 58 & Ganado & 44 & Cítricos & 42 \\
Bosque para leña & 32 & Pavos & 24 & Viveros & 29 \\
Bosque maderero & 36 & Conejos & 14 & Café & 23 \\
Hortalizas & 50 & Garrobos & 16 & Chiles & 24 \\
Cacahuete & 15 & Cabras & 13 & Loroco & 38 \\
Gallineros & 55 & Apiarios & 24 & Verduras & 44 \\
Caña de azúcar & 19 & Cerdos & 29 & Total de actividades & 20 \\
\hline
\end{tabular}

* Los números hacen referencia al número de comunidades en las cuales se cuenta con tierra, agua y/o experiencia para iniciar tales proyectos.

La diversidad de actividades informadas es sorprendente y algunas totalmente novedosas. Cubren un amplio espectro que va desde la agricultura de exportación tradicional, café y caña de azúcar, hasta algunas especies menores que sólo en años recientes se han comenzado a exportar a Estados Unidos, como son los garrobos. También se mencionan actividades pecuarias muy tradicionales como la avicultura, los apiarios y la porcicultura hasta la cunicultura que en nuestro país es incipiente. También se hace mención de las hortalizas y verduras cuya práctica ha sido tradicional junto a los lorocos, cultivo muy novedoso, sin dejar de lado algunos que ya se introdujeron, como los chiles y el cacahuete.

Si efectivamente las comunidades lograran poner en marcha toda esta gama de proyectos agropecuarios, unidos a los no agrícolas, pero para los cuales se tiene mano de obra recientemente calificada, las posibilidades de alcanzar un desarrollo endógeno y sostenible serían muchas.

Para salir adelante con todas estas iniciativas, las comunidades cuentan con excelentes niveles de organización y participación en las distintas actividades consultivas y resolutivas de la comunidad, además de aceptables niveles de conciencia acerca de las ventajas del trabajo comunitario.

Dada la importancia que tiene la participación, no sólo para el individuo sino para la buena marcha de la comunidad, a manera de ejemplo presen- tamos la participación de la población en las asambleas comunitarias. Valga aclarar que todas las comunidades estudiadas están organizadas. Y es que la organización es el primer requisito para considerar a cualquier comunidad como sujeto de la nueva iniciativa, como agente del desarrollo económico comunitario. En el Cuadro 31 se puede observar su participación en las asambleas, las cuales, sin ser la única forma de participación y tampoco la más agradable, nos indican también el interés de las personas en los asuntos de su comunidad.

\section{Cuadro 31}

Participación de los miembros de la comunidad en asambleas comunitarias

\begin{tabular}{llr}
\hline ¿Qué tanto & Siempre & 41 \\
se participa & Casi siempre & 38 \\
en las & A veces & 18 \\
asambleas & Nunca & 1 \\
comunitarias? & No contesta & 2 \\
\hline
\end{tabular}

Ciertamente los niveles de participación reportados, como se muestra en el Cuadro 31, son bastante altos. El que un $\mathbf{4 1}$ por ciento participe siempre y un 38 por ciento casi siempre nos indica un nivel de participación de casi el 80 por ciento en forma regular y constante. Seguramente cualquier 
organización gremial clamaría por conseguir tales niveles de participación. Y lo más sorprendente es que no se trata de la mera asistencia a las reuniones, sino que desarrollan una participación activa, en la cual dejan oír con mucho entusiasmo su voz, como lo pudimos comprobar en más de alguna de nuestras visitas a las comunidades.

\section{La mujer en las comunidades}

En la vida cotidiana rural, así como en las circunstancias excepcionales generadas por la guerra civil, a la mujer le ha tocado desempeñar un rol mucho más protagónico que el habitual. Esas condiciones acompañan también la construcción de la nueva alternativa de desarrollo y la mujer continúa siendo guía, responsable y baluarte principal. Tal realidad es evidente en cualquier comunidad, pero se hace sorprendente en comunidades como Nuevo Gualcho, en la cual la mayoría de habitantes son mujeres.

Cuadro 32

La problemática del género en las comunidades

\begin{tabular}{lccc}
\hline & Sí & No & No contesta \\
\hline $\begin{array}{l}\text { Existen hogares domde la } \\
\text { mujer es la jefa de familia }\end{array}$ & 89 & 9 & 2 \\
$\begin{array}{l}\text { Las mujeres poseen } \\
\text { alguna organización }\end{array}$ & 41 & 58 & 1 \\
$\begin{array}{l}\text { Se han impartido } \\
\text { seminarios sobre género }\end{array}$ & 29 & 71 & - \\
$\begin{array}{l}\text { Existen proyectos } \\
\text { económicos para mujeres }\end{array}$ & 37 & 57 & 6 \\
\hline
\end{tabular}

Pero bien, de las comunidades estudiadas, en la mayoría las mujeres son jefas de familia, con todas las implicaciones que ello trae consigo, esto es, tener la responsabilidad material y espiritualmoral de que ese hogar exista, funcione y se desarrolle (ver Cuadro 32).

No deja de ser alentador que en 41 por ciento de las comunidades exista algún tipo de organización de mujeres, ya que ello no sólo posibilita su desarrollo individual sino también colectivo, a la vez que se va generando una dinámica de capacitación en la teoría de género y se elevan los niveles de autoestima de ellas, los cuales muy a menudo están muy bajos en nuestro medio, inclusive, entre las mujeres profesionales e intelectuales.
Pero la organización no sólo potencia el desarollo espiritual y psicológico de las mujeres, sino que abre muchas posibilidades para mejorar las condiciones económicas que posibiliten una vida mejor y más digna para sí y para la familia. Así lo demuestra el Cuadro 32, donde se observa que en 29 comunidades se han impartido seminarios sobre género, y en 37 existen proyectos económicos dirigidos a favorecer las finanzas de las mujeres.

Todo ello es sumamente satisfactorio, ya que a diferencia de la comunidad campesina tradicional en la cual la mujer es víctima de las prácticas machistas de su marido, en especial, y de los hombres de su comunidad, en general, en estas comunidades, que buscan una altemativa real de desarrollo y vida, social, familiar e individual, observamos que también en materia de género se presentan cambios muy gratos.

\section{Los desastres naturales}

Cuando se trata de comunidades agropecuarias es de suma importancia considerar dentro del marco de un diagnóstico socioeconómico la presencia o no de desastres naturales en las comunidades estudiadas, ya que una inundación o una sequía pueden marcar diferencias anuales significativas en su actividad económica, lo cual se puede traducir en el éxito o fracaso de uno o más proyectos. Esto es de suma trascendencia a fin de evaluar la eficacia o ineficacia, etc. de una determinada alternativa de desarrollo económico. En el Cuadro 33 se muestran los resultados.

\begin{tabular}{llr}
\multicolumn{3}{c}{$\begin{array}{c}\text { Cuadro 33 } \\
\text { Desastres naturales sufridos } \\
\text { por las comunidades }\end{array}$} \\
\hline ¿Cuáles & Lluvias & \\
han sido & Vientos & 11 \\
los principales & Inundaciones & 24 \\
desastres & Deslizamientos de tierra & 19 \\
naturales? & Sequías & 6 \\
& No contesta & 15 \\
\hline
\end{tabular}

Los desastres naturales más graves son las inundaciones y son precisamente los que padecen la mayoría de comunidades de la zona costa. Debido a ellas no sólo se pierden las cosechas y los animales, sino también las viviendas y los utensilios domésticos, cuando no la vida de alguna persona. 
Lo lamentable de esta situación es que ha sido padecida por casi un quinto de las comunidades estudiadas y seguramente tales inundaciones han incidido en forma negativa en sus actuales condiciones de vida y de trabajo. Pero las comunidades también han sufrido a causa de los vientos huracanados, los cuales son una desgracia cuando actúan sobre las cosechas ya que las destruyen. Tal desgracia natural ha estado presente en casi una cuarta parte de las comunidades. Semejante es el caso de las lluvias cuando se presentan a destiempo, esto es, muy tarde en la temporada lluviosa ya que entonces echan a perder las cosechas de café o ajonjolí, por ejemplo, ocasionando fuertes pérdidas económicas. Finalmente encontramos las sequías, las cuales afectan, de manera principal, a la parte más sensible de las comunidades como son los cultivos de granos básicos, ya que de ellos depende su alimentación diaria. Las sequías las han sufrido, por lo menos, 15 comunidades.

De manera, pues, que las condiciones de vida material en estas comunidades estudiadas podría ser mejor si no hubiesen experimentado tanto desastre natural, ya que éstos no sólo destruyen recursos materiales existentes, sino que insumen recursos nuevos a los que podría darse un mejor uso, al menos, un destino productivo que contribuyera a la reproducción ampliada de la economía comunitaria.

Bien, con este apartado finalizamos este capítulo destinado al diagnóstico socioeconómico de 100 comunidades. A continuación intentaremos efectuar algunas reflexiones y conclusiones además de sugerir algunas propuestas que contribuyan al desarrollo económico comunitario.

\section{Consideraciones finales}

\subsection{Reflexiones}

Después de más de tres años de sentir la necesidad de contar con una información más general acerca de las comunidades existentes en el país, hemos logrado recabar, por fin, durante 1997, alguna información sistematizada de cien comunidades de repatriados, repobladores y combatientes desmovilizados, a los cuales consideramos como sujetos de una nueva estrategia de desarrollo que en algunos círculos intelectuales se le denomina: Desarrollo Económico Comunitario.

Esos sujetos, los habitantes de esas comunidades, son los que día con día objetivan en sus vidas y quehaceres una nueva realidad a la que denominamos anteriormente Nueva Economía Popular. Le denominamos "Nueva" porque la mera existencia de una economía popular no es nueva, pero en la forma en que ahora se presenta u ocurre sí lo es, ya que se da de manera organizada, buscando alcanzar el bienestar colectivo y mediante la práctica de nuevos valores de solidaridad, comunidad, cooperación, ayuda mutua, etc., y ello sí es nuevo y novedoso. Por tanto, para diferenciarla de las prácticas del pasado, aquellas de los campesinos tradicionales, es preciso llamarla de otra manera y buscando destacar su carácter popular.

Ahora bien, a esa actividad realizada de manera novedosa, que no se reduce al plano económico y busca conseguir el bienestar material y espiritual de las poblaciones involucradas mediante su propio esfuerzo organizado, es a lo que se llama Desarrollo Económico Comunitario. Es claro que el desarrollo no puede ser únicamente desarrollo económico y si a esta estrategia se le añade lo económico es para destacar un hecho característico de la estrategia popular, que es el de buscar desarollar, en forma primaria y por cuenta propia, de manera colectiva y organizada, las actividades económicas como medio para alcanzar el desarrollo, esto es, la satisfacción de buena manera de las necesidades materiales y espirituales.

Compartimos la idea de que el desarrollo presupone el crecimiento económico, pero también es obvio que el solo crecimiento económico no conduce necesaria e indefectiblemente al desarrollo económico, de allí que sin entrar en una discusión a menudo bastante escolástica en tomo al uso de los términos desarrollo, desarrollo económico o desarrollo socioeconómico, propugnamos por la nominación de desarrollo económico comunitario para destacar lo señalado antes.

$Y$ es que en las comunidades existe cierta claridad acerca de que la mejor manera de acceder al desarrollo es contando con un empleo y un ingreso 
que posibiliten la satisfacción de las necesidades materiales y espirituales. Pero como ese empleo y el ingreso derivado no lo generan otros de manera suficiente, al menos en los últimos tiempos, es preciso que lo generen los propios interesados, lo cual implica necesariamente incursionar en las actividades económicas. Hacerlo de manera individual y aisladamente está probado que no funciona, y esa es la razón de hacerlo de manera colectiva y organizada.

Los resultados aún no son todo lo satisfactorios que podrían ser, pero lo que sí queda claro en este estudio es que existen muchas potencialidades aún no desarrolladas, razón por la que en otras ocasiones hemos mencionado que "la mayor riqueza del esfuerzo comunitario no está en lo logrado sino en sus potencialidades".

Por otra parte es preciso aclarar, para evitar los prejuicios "anticolectivistas", que lo colectivo no se aplica mecánicamente a nada, ni a la propiedad de la tierra y de los medios de producción, ni al trabajo productivo, ni a la gestión de recursos financieros, ni a la comercialización de lo producido, sino que está presente en aquello en que resulte ser la forma más funcional. Por ejemplo: si la producción exige trabajo colectivo, pues, se hace de manera colectiva. O si la comercialización es más conveniente realizarla de manera colectiva y no individual, pues así se procede.

Pero quizá lo más importante es que no existe ninguna autoridad superior que le imponga a la comunidad la modalidad colectiva o individual, son sus gentes quienes deciden lo más conveniente. Y si esto vale para la propiedad y el trabajo, los dos factores más importantes dentro de la comunidad, es obvio que vale para todo. Tales hechos son, entre otros, los que nos animan y autorizan a insistir en que estas personas más que agentes o actores son sujetos. Sujetos de su vida y su trabajo, sujetos de su propio destino.

Dentro de esta estrategia de desarrollo, los sujetos de la misma son los habitantes de las comunidades organizadas o, si se prefiere, las comunidades organizadas, las cuales pueden ser muy grandes o muy pequeñas, conformar un conjunto mayor como una federación, un sistema, o permanecer como una sola unidad. Lo que importa es que la uni- dad básica es la comunidad y, por tanto, no resulta relevante una discusión del desarrollo en términos del espacio o del tamaño.

Las discusiones en torno al desarrollo local o desanollo regional desde la perspectiva del desarrollo económico comunitario (DEC) resultan intrascendentes, ya que éste puede ser pensado a nivel local, regional o nacional; en una pequeña comunidad $o$ en un grupo enorme de comunidades organizadas. De cualquier forma, la unidad básica seguirá siendo la comunidad.

Resulta obvio que la interrelación comunitaria es deseable y necesaria, ya sea en el ámbito económico como en el político o social, como factores potenciadores del desarrollo, pero el ámbito regional, por ejemplo, no se concibe como un factor predeterminante para la existencia del desarrollo económico comunitario, esto es, que mientras no se tenga una estrategia regional de desarrollo no sería posible pensar en el desarrollo.

Nuestra idea del DEC es que va de lo pequeño a lo grande, de lo local a lo regional, de lo simple a lo complejo, de lo comunal a lo nacional; esa es nuestra concepción procesal del mismo. Y es que en tanto que desarrollo no es concebible si no es como proceso y en tanto que proceso exige además poseer una concepción del mismo que sea abierta, no sólo a su propia dinámica de desarrollo, sino que a otras perspectivas, las cuales no tienen por que ser, necesariamente, excluyentes. Así, para el caso, las concepciones de desarrollo local, como ya lo apuntábamos supra, y del desa- 
rrollo regional, pueden ser perfectamente incluidas dentro de la perspectiva del DEC.

\subsection{Conclusiones}

- La primera conclusión tiene relación con la importancia poblacional del sector involucrado con la estrategia de Desarrollo Económico Comunitario. A nivel nacional hemos mostrado la presencia de una realidad inédita: la existencia de un sector comunitario que busca de manera organizada resolver sus problemas de pobreza y marginación... y lo están logrando.

- La segunda conclusión hace referencia a la toma de conciencia de las comunidades acerca de la importancia de legalizar su existencia, de allí que la gran mayoría ya tenga personería jurídica.

- La tercera, vinculada con la anterior, es el hecho de que la gran mayoría de comunidades sean, o estén en proceso de ser, propietarias de la tierra de la cual se derivan grandes ventajas para las comunidades.

- Una cuarta conclusión es que si bien existen problemas ambientales, también hay conciencia de enfrentarlos y lo están haciendo.

- En quinto lugar, en las comunidades estudiadas existe una diversificación de las actividades económicas bastante grande, si consideramos los principales oficios que presentan sus integrantes. Esto indica el elevado potencial de desarrollo que tienen sus habitantes.

- La sexta conclusión se refiere a las oportunidades de empleo, las cuales son insuficientes en la inmensa mayoría de comunidades, por lo que constituye uno de los problemas por enfrentar decidida y urgentemente.

- Asociado al problema anterior se encuentra el de los ingresos, los cuales son mayoritariamente bajos pese a las precisiones que tuvimos que efectuar a fin de lograr una mayor objetividad en la información. Sin embargo, mientras las oportunidades de empleo sean insuficientes, los ingresos también serán bajos para la mayoría de familias.

- La estrategia de vida del modelo económico agroexportador ya no opera en las comunidades, las cuales obtienen sus ingresos principalmente del trabajo en las comunidades.
- Las familias de las comunidades tienen como estrategia de ahorro la crianza de aves, puercos y cabros. Ello también contribuye en mayor o menor medida a satisfacer la dieta alimenticia diaria.

- La estrategia de desarrollo comunitario se visualiza como exitosa si consideramos las condiciones de vida de las familias comunitarias, las cuales presentan cantidades significativas: buenas condiciones de vida, ya sea por las condiciones materiales de la vivienda, la presencia de servicios públicos como agua y energía eléctrica, educación y salud, etc.

- Gran parte del éxito de las comunidades está asociado a la colaboración material, humana y técnica de las distintas ONG's que las acompañan.

- Las comunidades no son unidades cerradas ni estancadas, sino todo lo contrario: se trata de comunidades abiertas y en crecimiento, lo cual, obviamente, constituye un factor muy serio de presión sobre los recursos económicos y los servicios sociales, de allí que las comunidades deben hacer planes y proyectos a mediano y largo plazo.

- La mayoría de comunidades gozan de rentabilidad social y solamente un tercio reporta pérdidas financieras, lo cual es necesario considerar y tratar con seriedad a fin de revertirlo.

Relacionado con la conclusión anterior existe otro hecho que es preciso destacar, y es que cuando las comunidades obtienen algún excedente económico, lo destinan en su mayoría a la reinversión lo cual les posibilita su crecimiento futuro.

- Las diferentes comunidades cuentan con recursos económicos que aún no están siendo usados, ya se trate de tierra, capacidad de riego, habilidades recientes, experiencia acumulada, proyectos e iniciativas que buscan el apoyo financiero para convertirse en realidad.

- Las condiciones actuales de vida en las comunidades son muy favorables para posibilitar el desarrollo, tanto de los enfoques de género como del desarrollo humano con fuerte contenido ambientalista, y que no se confunda con el enfoque del desarrollo humano sostenible, ya que no nos referimos al mismo porque no es 
tal la experiencia en las comunidades.

- Finalmente, las comunidades estudiadas son, sin lugar a dudas, una exitosa experiencia de Desarrollo Económico Comunitario y, por tanto, es preciso apoyarlas puesto que si bien muestran excelentes resultados, se trata de una realidad que aún necesita consolidarse para potenciarse y reproducirse en gran escala.

\subsection{Recomendaciones}

Es imposible llegar al final de un trabajo de esta naturaleza y no sentir la necesidad de sugerir alguna idea o de formular alguna propuesta que pueda ayudar a mejorar las condiciones de la vida comunitaria.

- En primer lugar, es necesario preservar el apoyo proveniente de las diferentes ONG's, tanto nacionales como internacionales, ya que las comunidades aún no pueden marchar por su pro- pia cuenta. Hay que considerar que muchas se iniciaron luego de los acuerdos de paz en 1992, con lo cual su vida es muy corta.

- Es de suma importancia que desarrollen y profundicen el entramado de relaciones económicas, sociales y políticas de las distintas comunidades entre sí, como mecanismo válido y seguro para hacerle frente a las influencias del mercado capitalista.

- Es sumamente necesaria y urgente la creación de un Centro con nivel universitario que realice investigaciones de manera constante sobre el sector y divulgue información sobre la vida y los sueños de las comunidades. Todo ello no sólo sería de ayuda para el desarrollo del sector, sino para que otros investigadores, otras ONG's o cualquier otro interesado en esta problemática del desarrollo, pueda tener conocimiento de la realidad que se vive en El Salvador. 